\title{
Transcriptional and free radical responses to LVAD therapy
}

Kajari Dhar ${ }^{1}$, Asmini KC ${ }^{1}$, Fang Qiu², Hesham Basma ${ }^{1}$, Krupa K. Savalia ${ }^{3}$, Jocelyn Jones ${ }^{3}$, Alexandra M. Moulton ${ }^{3}$, Matthew C. Zimmerman ${ }^{3}$, John Um, Daniel Anderson ${ }^{1}$, Marshall Hyden ${ }^{1}$ and Brian D. Lowes ${ }^{1,5^{*}}$ (i)

\begin{abstract}
Background: Myocardial recovery with Left ventricular assistant device (LVAD) therapy is dichotomous with some patients obtaining remission from end-stage heart failure whereas most require transplantation or remain on pump support long term. Our goal was to determine transcriptional and free radical responses to LVAD treatment.

Methods: Tissues were collected from patients before and after LVAD placement in non-ischemic dilated cardiomyopathy patients $(n=14)$ along with controls $(n=3)$. RNA sequencing (RNASeq) analysis quantified transcriptional profiles by using a custom targeted panel of heart failure related genes on the PGM sequencer. The differential expression analysis between groups was conducted using edgeR (Empirical analysis of digital gene expression data in R) package in Bioconductor. Ingenuity Pathway Analysis (IPA) was carried out on differentially expressed genes to understand the biological pathways involved. Electron Paramagnetic Resonance (EPR) Spectroscopy was utilized to measure levels of free radicals in whole blood collected pre- and post-LVAD implantation $(n=16)$.
\end{abstract}

Results: Thirty-five genes were differentially expressed in pre-LVAD failing hearts compared to controls. In response to LVAD therapy, only Pyruvate dehydrogenase kinase 4 (PDK4) and period circadian protein homolog 1 (PER1) were altered with 34 heart failure related genes still differentially expressed post-LVAD compared to controls. IPA showed that DNA methylation-related genes were upregulated in both pre- and post-LVAD and was persistent with a Z-score of 2.00 and 2.36 for DNA Methyltransferase 3A (DNMT3A) and DNA methyltransferase 3B (DNMT3B), respectively. Inhibition of micro RNA21 (mir21) was also significant on pathway analysis in the post-LVAD population with a Z-score of -2.00 . Levels of free radicals in blood of pre- and post-LVAD patients did not change significantly.

Conclusion: LVAD therapy does not reverse many of the transcriptional changes associated with heart failure. Persistent changes in gene expression may be related to ongoing oxidative stress, continued DNA methylation, or changes in metabolism. PDK4 is a key regulator of glucose metabolism and its increased expression by LVAD therapy inhibited pyruvate metabolism.

Keywords: LVAD, Gene expression, Heart failure, Pyruvate, Dilated cardiomyopathy, Free radicals

\footnotetext{
* Correspondence: Brian.Lowes@unmc.edu

William Dodge Angle Professor of Cardiology

'Department of Cardiology, University of Nebraska Medical Center, Omaha,

USA

${ }^{5}$ William Dodge Angle Professor of Cardiology, 982265 Nebraska Medical

Center, Omaha, Nebraska 68198-2265, USA

Full list of author information is available at the end of the article
}

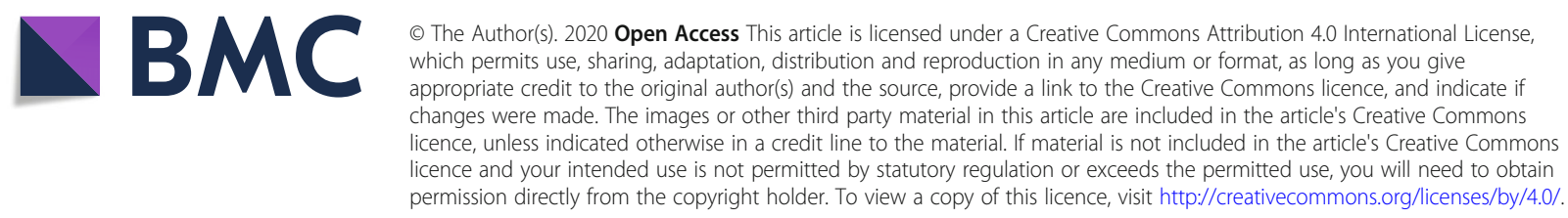




\section{Background}

Non-ischemic dilated cardiomyopathies are a major cause of illness and death in humans [1]. Advanced therapies like cardiac transplantation are often not a viable option for patients due to the limited donor supply. LVADs are mechanical pumps used to support some patients with advanced heart failure as bridge-to-transplant therapy or destination therapy to improve quality of life [2]. The number of patients receiving LVADs as treatment of advanced heart failure has recently increased. While these devices provide immediate improvement in cardiac output and quality of life, significant problems remain such as death due to infections, ongoing heart failure, strokes, and device malfunctions [3]. Furthermore, recovery of heart function and device explant is rare with many patients deteriorating over time [4].

Prior studies suggest that failure of assist devices to produce sustained myocardial recovery may be due to persistence of fetal transcriptional patterns of contractile and metabolic genes $[5,6]$. The cause of these continued changes are unknown but it has been suggested that LVAD therapy increases oxidative stress, and that these patients have abnormalities in DNA repair mechanisms and ongoing DNA damage [7]. Oxidative stress can be defined as an imbalance between antioxidant defenses and the production of reactive oxygen species (ROS), which at high levels cause cell damage but at lower levels induce indirect changes in intracellular signaling pathways [8]. Increased oxidative stress is associated in most types of HF, including that resulting from ischemic and non-ischemic cardiomyopathy [8].

Next generation sequencing of RNA and DNA allows high-throughput sequencing of entire genome or targeted genes at a rapid and low cost for the purposes of quantifying changes in gene expression or studying mutations [9]. It can assist in identifying and validating pathways involved in the pathophysiology of disease progression in advanced heart failure [4]. Our goal was to evaluate transcriptional changes and free radical responses to LVAD therapy.

\section{Methods}

Tissue collection protocols, procedures and archival in the Nebraska Cardiovascular Biobank and Registry were approved by the Institutional Review Board (IRB) of The University of Nebraska Medical Center following guidelines in the declaration of Helsinki. The IRB numbers were added in ethical approval section. All patients signed informed written consent for the collection and use of tissue samples prior to donation. The left ventricular apex tissues were obtained from the Nebraska Cardiovascular Biobank from 14 non-ischemic dilated cardiomyopathy patients at time of LVAD placement (pre-LVAD) and also during transplantation (post-
LVAD). Control tissues from non-failing hearts not utilized for transplant were obtained from the left ventricular free wall from patients who had brain death but normal heart function on imaging. These hearts are normally used for heart transplant if an acceptable recipient is available. They are not normal or healthy donors but their cardiac function is preserved or "non-failing". Patients in this study were all the heartmate II for a duration of 293 days. The heartmate II is a left ventricular assistance device that is implanted in left ventricular to provide circulatory support in chronic heart failure patients. Tissues were immediately placed into Allprotect (Qiagen, Germantown, MD) solution to stabilize mRNA. Tissue was then further dissected in the lab and aliquots were made, placed in Allprotect, and frozen at -70 until use. An additional 16 patients had blood drawn at the time of LVAD implant and post-LVAD for measurement of free radicals. Our RNA library construction, targeted DNA template and sequencing were performed, as we previously described [4]. The study targeted 140 genes were previously identified by quantitate RT PCR, gene arrays and next generation sequencing has been associated with heart failure $[4,5,10-16]$.

\section{RNA isolation}

RNA was isolated from approximately $10 \mathrm{mg}$ of myocardial tissue with the RNeasy ${ }^{\circ}$ Mini Kit (Qiagen ${ }^{\circ}$ ). Qubit 2.0 fluorimeter (Invitrogen, Life Technologies) was used to obtain quantitative measurement of the RNA.

\section{RNA library construction}

10 ng of RNA, isolated from the cardiac tissue, was reverse transcribed to synthesize complementary deoxyribonucleic acid (cDNA) using the Ion AmpliSeq ${ }^{\mathrm{Tm}}$ RNA RT Module and Applied Biosystems thermal cycler. Target sequences were amplified using Ion AmpliSeq ${ }^{\text {Tix }}$ RNA Custom Panels and Library Kit (Life Technologies). Our custom panel targeted 140 cardiac, inflammatory, and other genes. Following the amplification, partial digestion of primer sequences was carried out using FuPa reagent from Ion AmpliSeq ${ }^{\mathrm{mm}}$ RNA Library Kit. Ion AmpliSeq $^{\text {TM }}$ adaptors were then ligated to the targeted deoxyribonucleic acid (DNA). Target DNA sequences were purified in a two-round purification process using Dynabeads $^{\bullet}$ Magnetic Beads which isolated and discarded excess primer sequences and high-molecular weight DNA from the solution. Next, library was amplified using Ion AmpliSeq ${ }^{\text {TM }}$ RNA Library Kit and purified with single-round purification using Dynabeads ${ }^{\oplus}$ Magnetic Beads. DNA library was quantitatively measured using the Qubit $^{\circ} 2.0$ fluorometer with Qubit ${ }^{\circ}$ dsDNA HS Assay kit. 


\section{Preparation of targeted DNA template}

Ion library preparation was prepared by appropriately diluting the amplified stock library. Emulsion polymerase chain reaction (PCR) on ion sphere particles was used to amplify diluted libraries with the Ion One Touch ${ }^{\text {Tu }} 2$ System. Ion One Touch ${ }^{\text {Tu }}$ Enrichment System was used to enrich the template-positive ISPs.

\section{Sequencing}

Sequencing was performed for all patients on the Ion Torrent Personal Genome Machine (PGM), utilizing the Ion 316 chip. Coverage analysis as well as mapping the reads and alignment was done using the Ion Torrent Browser Suite ${ }^{\mathrm{TM}}$.

\section{Statistical analysis}

RNA-sequencing data was collected for control condition $(n=3)$, and before and after receiving LVAD conditions $(n=14)$, and then filtered to remove genes with very low reads. The expression of each gene on the cardiac panel was assessed in proportion to the total reads on the chip. The data normalization and differential expression analysis was conducted using edgeR (Empirical analysis of digital gene expression data in R) package in Bioconductor developed by Robinson et al. [17, 18]. The normalization factors for the data were estimated by the trimmed mean of the M-values normalization method in the edgeR package and used to adjust for varying sequencing depths and potentially other technical effects across samples. We aimed to test if genes are differentially expressed among 3 conditions: pre- and postreceiving LVAD, and control. The Benjamini Hochberg method was used to estimate the false discovery rate (FDR) and statistical significance was accepted at FDR adjusted $\mathrm{p}$-value $<0.05$.

\section{Ingenuity pathway analysis}

To further evaluate the biological pathways, log fold change utilizing IPA was carried out on the targeted panel genes between pre and post LVAD.

\section{Free radical measurement}

We utilized EPR Spectroscopy (a.k.a. ESR Spectroscopy) to measure levels of free radicals in whole blood collected from heart failure patients pre- and post-LVAD implantation. EPR Spectroscopy is one of the most sensitive and definitive methods for measuring short-lived, reactive molecules known as free radicals (i.e. molecules with an unpaired electron). We utilized the cellpermeable, free radical-sensitive spin probe, 1-hydroxy3-methoxycarbonyl-2, 2, 5, 5-tetramethylpyrrolidine $(\mathrm{CMH}) . \mathrm{CMH}$ is oxidized by free radicals to form a stable nitroxide radical $\left(\mathrm{CM}^{*}\right)$ with a half-life of several hours at physiological $\mathrm{pH}$ and temperature. Importantly, this stable $\mathrm{CM}^{*}$ is detectable by EPR spectroscopy resulting in an EPR spectrum whose amplitude is directly proportional to the levels of free radicals in the sample. For our studies, whole blood was collected from heart failure patients and immediately incubated with $\mathrm{CMH}$. After this incubation, the blood sample was inserted into a Bruker E-scan EPR Spectrometer that is housed in the EPR Spectroscopy Core at the University of Nebraska Medical Center. EPR spectrum were obtained from each sample and the amplitude was quantified [19].

\section{Results}

\section{Patient characteristics}

We analyzed tissue on 14 patients who had LVAD placement and subsequent transplant along with 3 normal hearts as controls. Heart failure patient's clinical and demographical information are shown in Table 1. Our sample population was $78 \%$ male and $100 \%$ Caucasian with an average age of 54 . All heart failure patients had end stage heart failure refractory to medical therapy and received LVAD support (100\% axial flow pump, Heartmate II). Historically type 2 diabetes, atrial fibrillation and hypertension were common. Ejection fraction of all heart failure patients was less than $25 \%$ at the time of LVAD placement. Average LVAD duration of patients was 293 days.

\section{Gene expression changes in heart failure and responses to LVAD therapy}

Analysis of 122 genes was available after filtering the data from sequencing. Table 2 shows that expressions of

Table 1 Heart Failure Patient Characteristics

\begin{tabular}{ll}
\hline Patients (n) & 14 \\
Age (year) & $54.5 \pm 14.63$ \\
Gender (\% Male) & 78.5 \\
Race (\%Caucasian) & 100 \\
Comorbid Illness (\%) & DM 50\%/HTN 100\%/Afib 50\%/CKD 57\% \\
LVEF at time of placement (\%) & $<25$ \\
LVAD duration (Days) & $293.28 \pm 212.51$ \\
\hline
\end{tabular}

LVEF Left Ventricular Ejection Fraction, DM diabetes mellitus, HTN Hypertension, Afib Afibrillation, CKD Chronic Kidney Disease 
Table 2 Expressions of same genes from pre and post LVAD patients were compared with control (normal heart function)

\begin{tabular}{|c|c|c|c|c|}
\hline Genes & $\begin{array}{l}\text { Pre LVAD } \\
\text { Log Fold Change }\end{array}$ & $\begin{array}{l}\text { Pre LVAD P-values } \\
\text { Unadjusted }\end{array}$ & $\begin{array}{l}\text { Post LVAD } \\
\text { Log Fold Change }\end{array}$ & $\begin{array}{l}\text { Post LVAD P-values } \\
\text { Unadjusted }\end{array}$ \\
\hline NPAS2 & -1.605275919 & 4.87094E-05 & -1.397723442 & 0.0007821 \\
\hline MYH6 & -2.669087096 & 5.31977E-05 & -2.174408706 & 0.0007685555 \\
\hline CAV3 & -1.707932338 & 8.79425E-05 & -1.70580784 & $1.79226 \mathrm{E}-05$ \\
\hline RPS18 & -1.784036157 & 0.00010296 & -1.532513748 & 0.002332871 \\
\hline VEGFA & -1.9420985 & 0.000148401 & -2.271725989 & 3.38603E-07 \\
\hline KCNIP2 & -2.115280577 & 0.000226768 & -2.113046896 & 0.005727492 \\
\hline MYL3 & -2.498739179 & 0.000300433 & -2.464807535 & 0.001070655 \\
\hline ABCC9 & 2.506677564 & 0.000512818 & 2.480693355 & 0.001362304 \\
\hline TAZ & -1.450228008 & 0.000833679 & -1.424198085 & 0.001730641 \\
\hline TNNC1 & -2.551724313 & 0.000911945 & -2.562617548 & 0.002380371 \\
\hline BAG3 & -1.597396575 & 0.000925165 & -1.391152514 & 0.002891381 \\
\hline HK2 & -1.746817258 & 0.00111143 & -1.765372871 & 0.00204897 \\
\hline BCL2L13 & -1.266480026 & 0.001220225 & -1.320725868 & 0.000458956 \\
\hline PLEKHA3 & 3.006631634 & 0.001301471 & 2.610379124 & 3.86136E-06 \\
\hline ATRNL1 & 3.662335117 & 0.00169003 & 4.0287555573 & 0.001271235 \\
\hline ACTC1 & -2.634399187 & 0.00189368 & -2.561656694 & 0.009567495 \\
\hline GLS & 1.71614315 & 0.002592714 & 1.707989608 & 0.001244745 \\
\hline UBE2B & 1.639008895 & 0.002871839 & 1.63245571 & 0.000969307 \\
\hline CCL4 & 6.86866137 & 0.003407897 & 7.014954165 & 0.00836106 \\
\hline WEE1 & 1.962736091 & 0.003521401 & 2.30452751 & 0.005741519 \\
\hline TBX2 & -1.466773894 & 0.003658799 & -1.70561214 & 0.0006502 \\
\hline SOD1 & -1.299284014 & 0.005732061 & -1.243696096 & 0.005174953 \\
\hline CRY1 & -1.533613797 & 0.006713156 & -1.200993733 & 0.037197353 \\
\hline LDB3 & -1.607768047 & 0.007365461 & -2.561656694 & 0.009567495 \\
\hline PDK4 & 2.336542961 & 0.0139209 & 4.294772562 & $3.72295 \mathrm{E}-06$ \\
\hline ACTN2 & 1.68167516 & 0.013140977 & 1.937477277 & 0.002374327 \\
\hline ALPL & -1.167406256 & 0.010718361 & -1.398953606 & 0.002603245 \\
\hline SMAD3 & -1.107144774 & 0.017122147 & -1.270954679 & 0.004133984 \\
\hline JUP & -1.019116 & 0.047965376 & -1.244178135 & 0.005235439 \\
\hline CXCL10 & 3.598467431 & 0.011522037 & 5.336797098 & 0.006169904 \\
\hline COX8A & -1.026853703 & 0.050187355 & -1.04518993 & 0.007325988 \\
\hline TGFB1 & 1.933692353 & 0.011185138 & 2.022138359 & 0.007540614 \\
\hline $\mathrm{DMD}$ & 1.257128687 & 0.037259302 & 1.414148957 & 0.007716551 \\
\hline PER2 & 2.138459293 & 0.016886363 & 2.312433775 & 0.013369433 \\
\hline PER1 & -1.612261379 & 0.000368588 & & \\
\hline
\end{tabular}

same genes from pre and post LVAD patients were compared with controls (non failing hearts). Differential expression was detected in 35 genes when comparing pre-LVAD and normal heart patients. Neuronal PAS domain protein 2 (NPAS2) and Myosin heavy chain 6 (MYH6), were the most significant finding based on $\mathrm{p}$ value and absolute log fold change ( $\mathrm{p}$-values, 0.000048 and 000053; log fold change -1.6 and -2.7 respectively). Thirty-four genes were identified to be differentially expressed between post- LVAD and non-failing hearts using cutoff adjusted p-value of 0.05. Vascular endothelial growth factor A (VEGFA) was the most significant finding in the post-LVAD population relative to nonfailing hearts $(p=.0000003$, log fold change -2.3$)$. Chemokine ligand 4 (CCL4) was the gene with the greatest change in expression relative to non-failing hearts in both the pre-LVAD (log fold change 6.8) and postLVAD groups (log fold change 7). Only 2 genes were 
expressed differentially between pre- and post-LVAD when adjusting for within-subject correlation. It was detected that PDK4 and PER1 were significantly higher in post-LVAD compared to pre-LVAD tissues (Fig. 1). PDK4 is elevated in heart failure and LVAD therapy increases PDK4 expression further. PER1 is decreased in heart failure. LVAD therapy improves PER1 but not resume to normal levels.

\section{Pathway analysis in IPA}

To further determine the upstream analysis, fold change of the targeted panel genes of pre- and post-LVAD compared to control were analyzed utilizing IPA. The DNA methyltransferase 3A and 3B catalyze the transfer of a methyl group to DNA and use S-adenosyl methionine (SAM) as the methyl donor. DNA methylation performs a wide variety of biological functions. Figure 2 shows that DNA methylation signals were upregulated in both pre- and post-LVAD and were persistent with a Z-score of 2.00 and 2.36 for DNMT3A and DNMT3B, respectively. However, inhibition of mir21 with a Zscore of -2.00 emerged Post LVAD. This inhibition represents a positive signal in the post-LVAD population. Running IPA analysis for pre- and post-LVAD in IPA

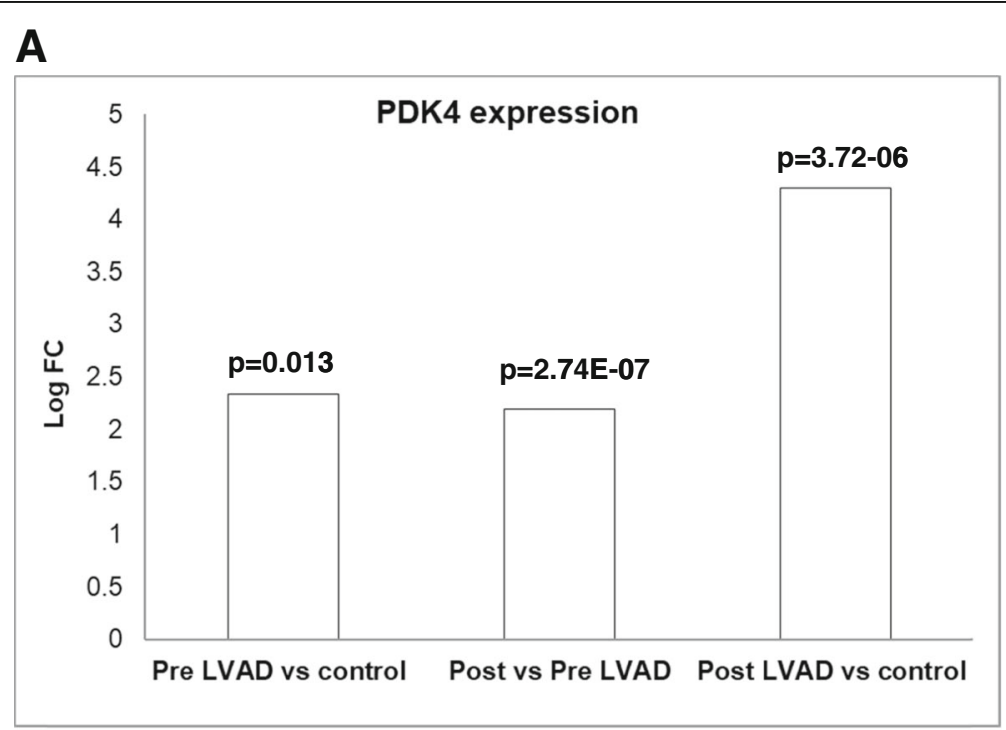

B

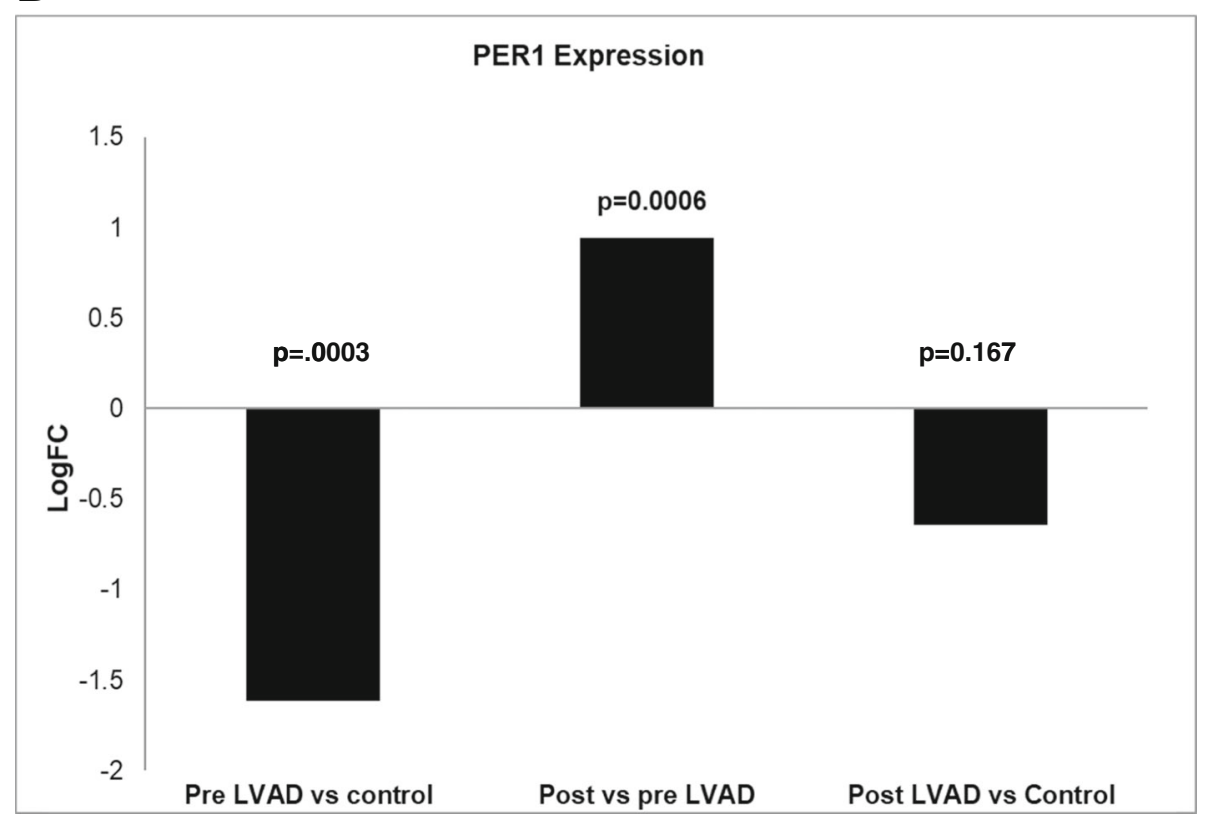

Fig. 1 Differential gene expressions levels with LVAD therapy. a PKD4 expressions compared with pre LVAD and control, pre and post LVAD and post LVAD and control. b PER1 expression compared with pre LVAD and control, pre and post LVAD and post LVAD and control 


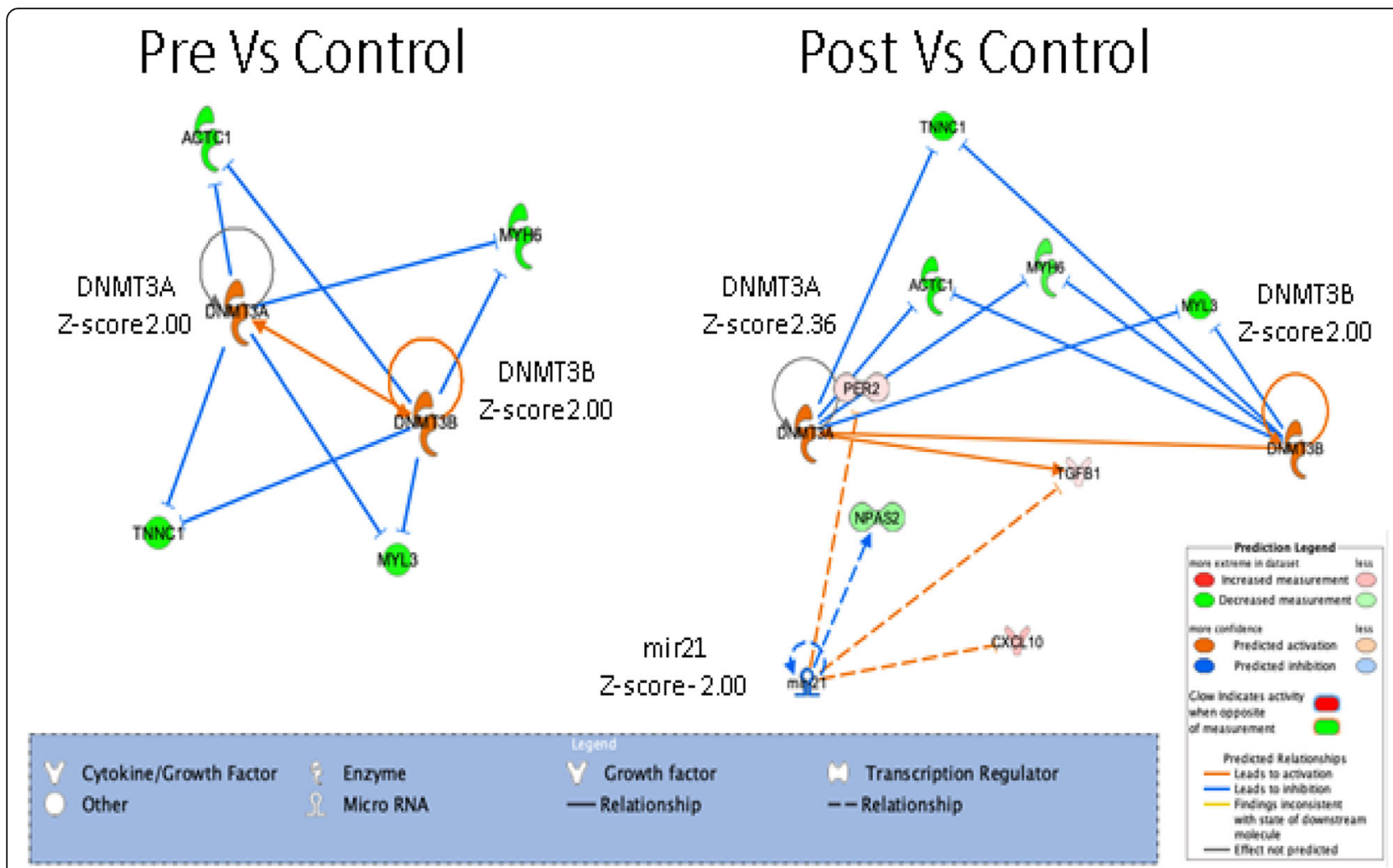

Fig. 2 Pathway analysis in IPA. Upstream analysis in IPA of fold change genes in Pre and Post compared to control. DNA methylation signals were upregulated in both pre- and post-LVAD with a Z-score of 2.00 and 2.36 for DNMT3A and DNMT3B, respectively. Inhibition of mir21 was observed with a Z-score of - 2.00 in Post LVAD. Dashed line (indirect interaction with other molecules), solid line (direct interaction with other molecules)

yielded a very narrow analysis since there are only 2 genes that were significantly different. However,

circadian rhythm signaling was the only major canonical pathway since PER1 was upregulated in post- versus pre LVAD.

\section{Free radicals did not change significantly with LVAD therapy}

Figure 3a shows the EPR spectrum amplitude in arbitrary units (a.u.) from individual whole blood samples collected pre- and post-LVAD from $\mathrm{n}=16$ heart failure patients. The summary graph (Fig. $3 \mathrm{~b}$ ) shows the mean \pm SEM of the EPR spectrum amplitude pre- and postLVAD. There was no significant difference in levels of free radicals between the pre- and post-LVAD groups $(\mathrm{p}=0.272)$.

\section{Discussion}

This study indicates that LVAD therapy does not reverse many of the transcriptional changes associated with heart failure and increased the expression of PDK4, a key regulator of glycolysis. Heart failure is a complex disease process where transcriptional changes contribute to contractile dysfunction, arrhythmias, and ultimately cell death [20]. These ongoing changes in gene expression likely contribute to poor rates of myocardial recovery post-LVAD therapy and ongoing issues with symptomatic heart failure as well as arrhythmias. LVADs are currently being utilized as destination therapy, bridge to transplantation or bridge to recovery. Despite the device indication only $1 \%$ of patients are being explanted for recovery of cardiac function suggesting new therapies or approaches are necessary to achieve this goal [21]. Long periods of changes in gene expression could be related to ongoing changes in metabolism or continued DNA methylation.

The main finding at this study is that LVAD therapy increases PDK4 expression. The heart consumes more energy than any other organ and is capable of metabolizing carbohydrates, fatty acids and amino acids in order to meet its needs. Measured metabolites of glucose metabolism, amino acids, creatinine and citric acid cycle intermediates are diminished in heart failure contributing to an overall energy depleted state [6]. Many of these metabolites are normalized with LVAD therapy along with improvements in hemoglobin $\mathrm{A} 1 \mathrm{C}$ (HbA1c), fasting plasma glucose, and daily insulin requirements [22]. Unfortunately, abnormalities the citric acid cycle persist 


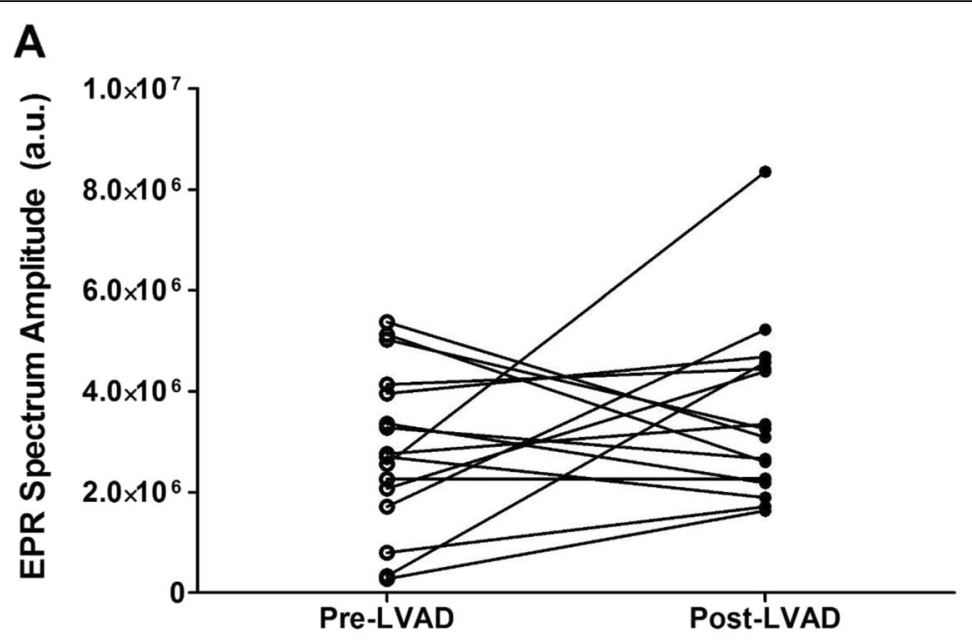

B

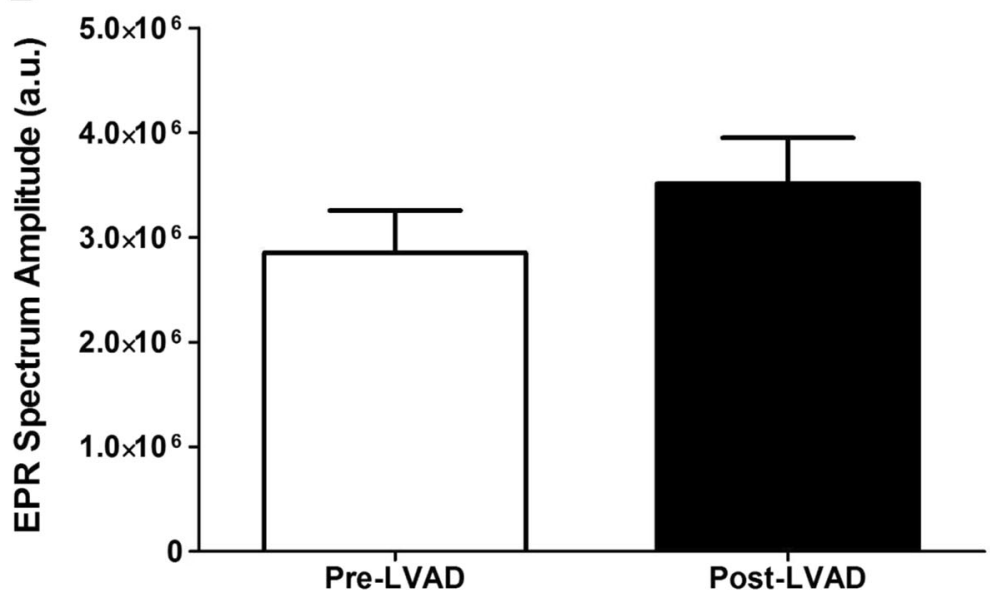

Fig. 3 Free radical levels in whole blood pre- and post-LVAD

post-LVAD likely contributing to ongoing contractile dysfunction $[6,23]$. In heart failure there is a switch from fatty acids ( $\beta$-oxidation) to carbohydrates (glycolysis) as a fuel preference [24]. PDK4 is a key regulator of glucose metabolism and it's expression is elevated in heart failure and worsened by LVAD therapy in the current study [25]. These changes would contribute to an ongoing preference for glycolysis over $\beta$-oxidation in heart failure and post-LVAD hearts. Both overexpression and under-expression of PDK4 can contribute to contractile dysfunction. For example, deficiency and mutation in PDK4 gene leads to apoptosis and dilated cardiomyopathy in Doberman Pinschers [26, 27], whereas PDK4 overexpression perturbs metabolism and worsens calcineurin-induced cardiomyopathy [28]. PDK expression is regulated by numerous ligands including insulin, epinephrine, and adiponectin, along with nuclear hormone receptors such as peroxisome proliferator-activated, glucocorticoid, estrogen, and thyroid receptors [29].
PER1 expression is decreased in heart failure and increased significantly in post-LVAD compared to preLVAD conditions (Fig. 1). PER1 is a clock gene and involved in rhythmic expression in human hearts [30]. PER1 also controls blood pressure and normalizes renal sodium transport protein levels [31]. Circadian clock proteins have potential effects on myocardial gene expression, metabolism, and function within hearts [32]. Circadian rhythm signaling was the only major pathway in IPA analysis when compared between post- and preLVAD hearts. Increased expression of PER1 was insufficient to alter the overall transcriptional profile of heart failure in these LVAD patients.

Oxidative stress contributes to numerous different diseases including diabetes and heart failure through activation of stress pathways involving serine/threonine kinases which have a negative effect on insulin signaling [33]. Excessive levels of ROS and free radicals can cause DNA damage, modify proteins and cause cellular injury. Excess generation of these reactive molecules can arise 
from several sources including mitochondria, $\mathrm{NAD}(\mathrm{P}) \mathrm{H}$ oxidase, xanthine oxidase and uncoupled nitric oxide synthase [8]. In this study, LVAD therapy did not impact levels of free radicals, as measured by EPR Spectrosopy. These chronic increases in free radicals likely contribute to a further decline in myocardial function and ongoing changes in myocardial gene expression. Pathway analysis suggests many of these changes are attributable to alterations in DNA methylation. Our results showed that inhibition of micro RNA21 (mir21) was also significant on pathway analysis in the post-LVAD population with a Zscore of -2.00 . Mir21 plays a vital role in vascular smooth muscle cell proliferation and apoptosis, cardiac cell growth and death, and cardiac fibroblast functions. Mir21 targeted Phosphatase and tensin homolog (PTEN), Programmed cell death protein 4 (PDCD4), Protein sprouty homolog 1 (SPRY1) and Sprouty homolog 2(SPRY2) and effects on their expression and eventually that influences on cardiovascular system [34]. Other groups have also demonstrated an increase in oxidative stress and abnormalities in DNA post-LVAD therapy [7, 35]. Mondal et al. also demonstrated that patients post-LVAD had higher levels of ROS, DNA damage in leukocytes and abnormalities in DNA repair. There are several possible explanations as to why LVAD therapy does not improve oxidative stress. Many patients with LVADs have ongoing issues with heart failure, arrhythmias, anemia due to hemolysis as well as inflammation from surgery or infections. While medicines can have antioxidant effects and aid myocardial recovery, guideline directed medical therapy is often poorly tolerated in patients with advanced heart failure, and poorly utilized after LVAD therapy. We previously have found only $1 / 3$ of patients are on beta-blockers 3 months postLVAD [36]. New approaches may be necessary to metabolically reprogram the heart after LVAD therapy in order to improve myocardial energetics and facilitate recovery.

Previous transcriptional studies utilizing oligonucleotide microarrays have shown that LVAD placement induces significant down regulation of myocardial and inflammatory gene expression including brain natriuretic peptide, collagen, dystrophin, interleukin 8, metaloprotein and tumor necrosis factor $\alpha(\mathrm{TNF} \alpha)$ [37]. Several recent studies have demonstrated that LVAD support results in alterations in gene expression, including (TNFo) [38, 39], Her2/neu, Her4 [27, 39] and glucose transporter 1 and 4 [40]. Further, Chen et al. have shown that Endothelial nitric oxide synthase (eNOS) and Dimethylarginine Dimethylaminohydrolase 1 (DDAH1) expression are significantly increased after LVAD support compared to pre-LVAD [41]. A recent study demonstrated a significant decrease in the expression of genes that boost a healthy immune response that was partially recovered after 6 months of LVAD support [42] and proteins involved in cytoskeleton and mitochondrial energy metabolisms significantly downregulated postLVAD [43].

This work was supported by a pilot grant to explore transcriptional changes in association of LVAD therapy along with changes to oxidative species. We plan additional studies with the next generation of left ventricular assist devices along with newer medical therapy to hopefully further aid recovery in this population.

\section{Limitations}

This study has several limitations. Only a targeted panel of genes previously demonstrated to be abnormal in heart failure were evaluated and much broader transcriptional changes are known to occur with LVAD therapy. Our analysis was confined to genes we previously have associated with contractile dysfunction in heart failure to limit false discovery. In addition, this study is limited to translational data and proteomics and metabolic studies are needed to further understand the biology of these changes. Our sample size was limited to 14 as part of a pilot study and patients were predominantly male Caucasians so our results may not be generalizable to the broader population. The scope of the current study does not allow for studying in depth bioinformatics of protein interactions and numerous confounders potentially exist. LVAD therapy continues to evolve and the next generation of LVADs is less thrombotic and has shown an improvement in clinical outcomes [44]. New pumps however, while more hemocompatible with patients, have not yet demonstrated improvements in myocardial recovery or remission from heart failure. Finally, the medical therapy of these patients was not standardized and it is not feasible to adjust

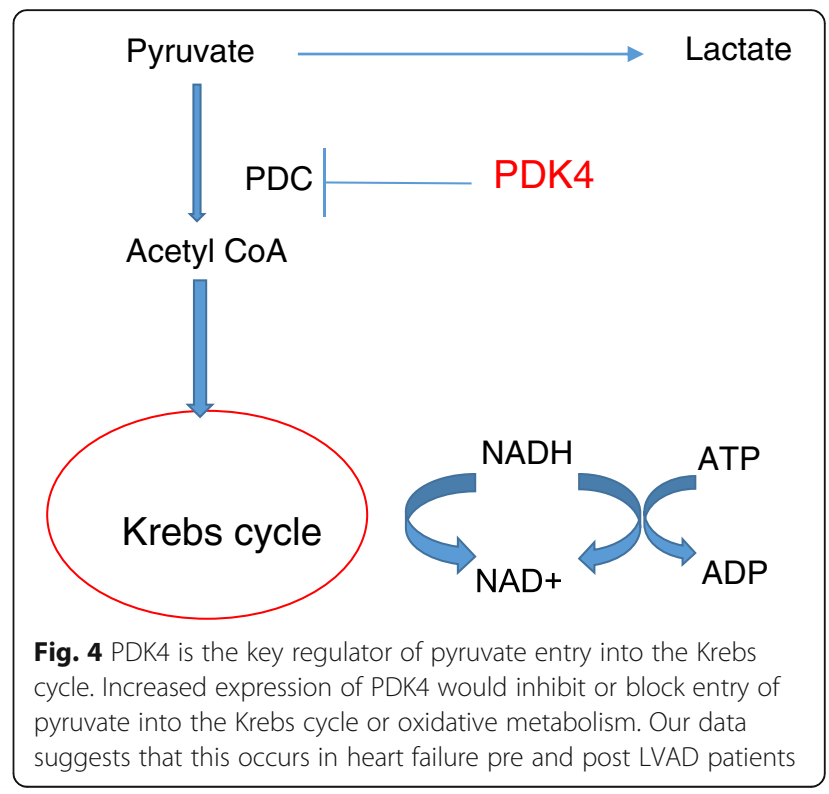


for the confounding effects of medications on gene expression or oxidative stress. Further studies are needed to better understand the mechanisms of cardiac recovery with LVAD therapy, interact action with newer devices, and risk factors for non-responders.

\section{Conclusions}

LVAD therapy does not reverse many of the transcriptional changes associated with heart failure. Persistent changes in gene expression maybe related to ongoing oxidative stress, continued DNA methylation, or changes in metabolism. PDK4 expression is increased by LVAD therapy suggesting alterations in glucose metabolism may be contributing to ongoing abnormalities in energy utilization (Fig. 4). Enhancing rates of myocardial recovery post-LVAD and improving long term outcomes with LVADs may require further therapies targeting metabolism, oxidative stress and epigenetic modifications.

\section{Supplementary information}

Supplementary information accompanies this paper at https://doi.org/10. 1186/s41231-020-00061-2.

Additional file 1.

\section{Abbreviations}

LVAD: Left Ventricular Assist Device; RNA: Ribonucleic Acid; PGM: Personal Genome Machine; edgeR: Empirical analysis of digital gene expression data in R; mRNA: messenger RNA; RNAseq: RNA sequencing; LVEF: left ventricular ejection fraction; PKD4: Pyruvate dehydrogenase Kinase 4; PER1: period circadian protein homolog 1; MYH-6: Myosin heavy chain 6; EF: ejection fraction; cDNA: complementary DNA; DNA: Deoxyribonucleic Acid; PCR: Polymerase chain reaction; ISPs: Ion sphere particles; $\triangle \mathrm{LVEF}$ : change in left ventricular ejection fraction; cpm: counts per million; IPA: Ingenuity Pathway Analysis; $\triangle E F$ : change in ejection fraction; miRNA: microRNA; EPR: lectron Paramagnetic Resonance; DNMT3A: NA methyltransferase 3A; DNMT3B: NA methyltransferase 3B; VEGFA: Vascular endothelial growth factor A; ROS: reactive oxygen species; $\mathrm{CMH}$ : 1-hydroxy-3-methoxycarbonyl-2, 2, 5, 5-tetramethylpyrrolidine); HbA1c: hemoglobin A1C; eNOS: Endothelial nitric oxide synthase; DDAH1: Dimethylarginine Dimethylaminohydrolase; Her2/ Her4: human epidermal growth factor receptor 2/4; CCL4: Chemokine ligand 4; NPAS2: Neuronal PAS domain protein 2; PTEN: Phosphatase and tensin homolog; PDCD4: Programmed cell death protein 4; SPRY1: Protein sprouty homolog 1; SPRY2: Sprouty homolog 2

\section{Acknowledgements}

This work was supported by the William Dodge Angle Endowment, NIH P20 HL101435, and PI: Lowes, Brian. EPR Spectroscopy data was collected in the University of Nebraska Medical Center's EPR Spectroscopy Core, which was established with support by a grant from the National Institute of General Medical Sciences of the National Institutes of Health (P30GM103335) awarded to the University of Nebraska's Redox Biology Center.

\section{Compliance with ethical guidelines}

This study was approved by the IRB at the University of Nebraska Medical Center. The IRB numbers are 133-14-EP with PI Dan Anderson and 477-17EP with PI Brian Lowes.

\section{Authors' contributions}

Drs. Um, Hyden Anderson and Lowes were responsible for patient care and recruitment. Dr. Dhar, Dr. Basma, Asmini KC, K Savalia and A Moulton were responsible for laboratory work and data analysis. Dr. Zimmerman was responsible for free radical data analysis and Dr. Qui was responsible for statistical analysis. The author(s) read and approved the final manuscript.

\section{Funding}

Not applicable.

Availability of data and materials

Data and materials are available.

Ethics approval and consent to participate

The IRB numbers are 133-14-EP with PI Dan Anderson and 477-17-EP with PI Brian Lowes.

\section{Consent for publication}

All authors give the Publisher the permission to publish the Work.

\section{Competing interests}

The authors declare that they have no competing interests.

\section{Author details}

${ }^{1}$ Department of Cardiology, University of Nebraska Medical Center, Omaha, USA. ${ }^{2}$ Department of Biostatistics, University of Nebraska Medical Center, Omaha, USA. ${ }^{3}$ Department of Cellular and Integrative Physiology, University of Nebraska Medical Center, Omaha, USA. ${ }^{4}$ Department of Surgery, University of Nebraska Medical Center, Omaha, USA. ${ }^{5}$ William Dodge Angle Professor of Cardiology, 982265 Nebraska Medical Center, Omaha, Nebraska 68198-2265, USA.

Received: 31 March 2020 Accepted: 26 May 2020

Published online: 02 June 2020

References

1. Mozaffarian D, Benjamin EJ, Go AS, Arnett DK, Blaha MJ, Cushman M, de Ferranti S, Despres JP, Fullerton HJ, Howard VJ, et al. Heart disease and stroke statistics--2015 update: a report from the American Heart Association. Circulation. 2015:131:e29-322.

2. Frazier $\mathrm{OH}$, Myers TJ. Left ventricular assist system as a bridge to myocardial recovery. Ann Thorac Surg. 1999;68:734-41.

3. Grady KL, Meyer PM, Mattea A, Dressler D, Ormaza S, White-Williams C, Chillcott S, Kaan A, Loo A, Todd B, et al. Change in quality of life from before to after discharge following left ventricular assist device implantation. J Heart Lung Transplant. 2003;22:322-33.

4. Dhar K, Moulton AM, Rome E, Qiu F, Kittrell J, Raichlin E, Zolty R, Um JY, Moulton MJ, Basma H, et al. Targeted myocardial gene expression in failing hearts by RNA sequencing. J Transl Med. 2016;14:327.

5. Lowes BD, Zolty R, Minobe WA, Robertson AD, Leach S, Hunter L, Bristow MR. Serial gene expression profiling in the intact human heart. J Heart Lung Transplant. 2006;25:579-88

6. Weitzel LB, Ambardekar AV, Brieke A, Cleveland JC, Serkova NJ, Wischmeyer $P E$, Lowes BD. Left ventricular assist device effects on metabolic substrates in the failing heart. PLoS One. 2013:8:e60292.

7. Mondal NK, Sorensen E, Hiivala N, Feller E, Griffith B, Wu ZJ. Oxidative stress, DNA damage and repair in heart failure patients after implantation of continuous flow left ventricular assist devices. Int J Med Sci. 2013;10:883-93.

8. Tsutsui H, Kinugawa S, Matsushima S. Oxidative stress and heart failure. Am J Physiol Heart Circ Physiol. 2011;301:H2181-90.

9. Lowes BD, Rome E, Dhar K, Kittrell J, Eudy JD, John Y, Moulton AM, J Z, Redder R, Anderson D, Raichlin E: Damaging cardiac and Cancer genetic variants in the LVAD population. VAD J 2015;1:1-11.

10. Abraham WT, Gilbert EM, Lowes BD, Minobe WA, Larrabee P, Roden RL, Dutcher D, Sederberg J, Lindenfeld JA, Wolfel EE, et al. Coordinate changes in myosin heavy chain isoform gene expression are selectively associated with alterations in dilated cardiomyopathy phenotype. Mol Med. 2002;8: 750-60.

11. Ambardekar AV, Walker JS, Walker LA, Cleveland JC Jr, Lowes BD, Buttrick PM. Incomplete recovery of myocyte contractile function despite improvement of myocardial architecture with left ventricular assist device support. Circ Heart Fail. 2011;4:425-32.

12. Kao DP, Lowes BD, Gilbert EM, Minobe W, Epperson LE, Meyer LK, Ferguson DA, Volkman AK, Zolty R, Borg CD, et al. Therapeutic molecular phenotype of beta-blocker-associated reverse-remodeling in nonischemic dilated cardiomyopathy. Circ Cardiovasc Genet. 2015;8:270-83.

13. Lowes BD, Baker ML, Blaxall BC. Gene expression profile of the recovering human heart. Eur Heart J. 2007;28:522-4. 
14. Lowes BD, Gilbert EM, Abraham WT, Minobe WA, Larrabee P, Ferguson D, Wolfel EE, Lindenfeld J, Tsvetkova T, Robertson AD, et al. Myocardial gene expression in dilated cardiomyopathy treated with beta-blocking agents. N Engl J Med. 2002:346:1357-65.

15. Lowes BD, Minobe W, Abraham WT, Rizeq MN, Bohlmeyer TJ, Quaife RA, Roden RL, Dutcher DL, Robertson AD, Voelkel NF, et al. Changes in gene expression in the intact human heart. Downregulation of alpha-myosin heavy chain in hypertrophied, failing ventricular myocardium. J Clin Invest. 1997;100:2315-24.

16. Sucharov CC, Kao DP, Port JD, Karimpour-Fard A, Quaife RA, Minobe W, Nunley K, Lowes BD, Gilbert EM, Bristow MR. Myocardial microRNAs associated with reverse remodeling in human heart failure. JCI Insight. 2017; 2:e89169.

17. McCarthy DJ, Chen Y, Smyth GK. Differential expression analysis of multifactor RNA-Seq experiments with respect to biological variation. Nucleic Acids Res. 2012;40:4288-97.

18. Robinson MD, McCarthy DJ, Smyth GK. edgeR: a bioconductor package for differential expression analysis of digital gene expression data. Bioinformatics. 2010:26:139-40.

19. Ahmad IM, Temme JB, Abdalla MY, Zimmerman MC. Redox status in workers occupationally exposed to long-term low levels of ionizing radiation: a pilot study. Redox Rep. 2016;21:139-45.

20. Severs NJ, Coppen SR, Dupont E, Yeh HI, Ko YS, Matsushita T. Gap junction alterations in human cardiac disease. Cardiovasc Res. 2004;62:368-77.

21. Kormos RL, Cowger J, Pagani FD, Teuteberg JJ, Goldstein DJ, Jacobs JP, Higgins RS, Stevenson LW, Stehlik J, Atluri P, et al. The Society of Thoracic Surgeons Intermacs database annual report: evolving indications, outcomes, and scientific partnerships. J Heart Lung Transplant. 2019;38:114-26.

22. Patel N, Gluck JA, Radojevic J, Coleman Cl, Baker WL. Left ventricular assist device implantation improves glycaemic control: a systematic review and meta-analysis. ESC Heart Fail. 2018:5:1141-9.

23. Diakos NA, Navankasattusas S, Abel ED, Rutter J, McCreath L, Ferrin P, McKellar SH, Miller DV, Park SY, Richardson RS, et al. Evidence of glycolysis up-regulation and pyruvate mitochondrial oxidation mismatch during mechanical unloading of the failing human heart: implications for cardiac reloading and conditioning. JACC Basic Transl Sci. 2016;1:432-44.

24. Karwi QG, Uddin GM, Ho KL, Lopaschuk GD. Loss of metabolic flexibility in the failing heart. Front Cardiovasc Med. 2018;5:68.

25. Zhang S, Hulver MW, McMillan RP, Cline MA, Gilbert ER. The pivotal role of pyruvate dehydrogenase kinases in metabolic flexibility. Nutr Metab (Lond). 2014;11:10.

26. Bolfer L, Estrada AH, Winter B, Taggart K, Lourenço F, Terada N, Byrne BJ, Conlon TJ, Pacak CA. The role of the pyruvate dehydrogenase kinase 4 (PDK4) gene mutation in the development of dilated cardiomyopathy in Dobermanpinschers and potential application of cardiac gene therapy. Mol Ther. 2016;24:S70-1.

27. Taggart K, Estrada A, Thompson P, Lourenco F, Kirmani S, Suzuki-Hatano S, Pacak CA. PDK4 deficiency induces intrinsic apoptosis in response to starvation in fibroblasts from Doberman pinschers with dilated cardiomyopathy. Biores Open Access. 2017;6:182-91.

28. Zhao G, Jeoung NH, Burgess SC, Rosaaen-Stowe KA, Inagaki T, Latif S, Shelton JM, McAnally J, Bassel-Duby R, Harris RA, et al. Overexpression of pyruvate dehydrogenase kinase 4 in heart perturbs metabolism and exacerbates calcineurin-induced cardiomyopathy. Am J Physiol Heart Circ Physiol. 2008;294:H936-43.

29. Jeong JY, Jeoung NH, Park KG, Lee IK. Transcriptional regulation of pyruvate dehydrogenase kinase. Diabetes Metab J. 2012;36:328-35.

30. Leibetseder V, Humpeler S, Svoboda M, Schmid D, Thalhammer T, Zuckermann A, Marktl W, Ekmekcioglu C. Clock genes display rhythmic expression in human hearts. Chronobiol Int. 2009;26:621-36.

31. Stow LR, Richards J, Cheng KY, Lynch IJ, Jeffers LA, Greenlee MM, Cain BD, Wingo CS, Gumz ML. The circadian protein period 1 contributes to blood pressure control and coordinately regulates renal sodium transport genes. Hypertension. 2012;59:1151-6.

32. Young ME. The circadian clock within the heart: potential influence on myocardial gene expression, metabolism, and function. Am J Physiol Heart Circ Physiol. 2006;290:H1-16.

33. Rains JL, Jain SK. Oxidative stress, insulin signaling, and diabetes. Free Radic Biol Med. 2011;50:567-75.

34. Cheng Y, Zhang C. MicroRNA-21 in cardiovascular disease. J Cardiovasc Transl Res. 2010;3:251-5.
35. Caruso R, Verde A, Campolo J, Milazzo F, Russo C, Boroni C, Parolini M, Trunfio S, Paino R, Martinelli L, et al. Severity of oxidative stress and inflammatory activation in end-stage heart failure patients are unaltered after 1 month of left ventricular mechanical assistance. Cytokine. 2012;59: 138-44.

36. Lundgren S, Lyden E, Stoller D, Hyden M, Burdorf A, Zolty R, Um J, Lowes B: Electrocardiographic characteristics, antiarrhythmic utilization, and outcomes in patients with left ventricular assist devices. VAD J 2018;4:1-15.

37. Blaxall BC, Tschannen-Moran BM, Milano CA, Koch WJ. Differential gene expression and genomic patient stratification following left ventricular assist device support. J Am Coll Cardiol. 2003:41:1096-106.

38. Razeghi P, Mukhopadhyay M, Myers TJ, Williams JN, Moravec CS, Frazier OH, Taegtmeyer $\mathrm{H}$. Myocardial tumor necrosis factor-alpha expression does not correlate with clinical indices of heart failure in patients on left ventricular assist device support. Ann Thorac Surg. 2001;72:2044-50.

39. Uray IP, Connelly JH, Thomazy V, Shipley GL, Vaughn WK, Frazier OH, Taegtmeyer $H$, Davies PJ. Left ventricular unloading alters receptor tyrosine kinase expression in the failing human heart. J Heart Lung Transplant. 2002; 21:771-82.

40. Chen Y, Park S, Li Y, Missov E, Hou M, Han X, Hall JL, Miller LW, Bache RJ. Alterations of gene expression in failing myocardium following left ventricular assist device support. Physiol Genomics. 2003;14:251-60.

41. Razeghi P, Young ME, Ying J, Depre C, Uray IP, Kolesar J, Shipley GL, Moravec CS, Davies PJ, Frazier OH, Taegtmeyer H. Downregulation of metabolic gene expression in failing human heart before and after mechanical unloading. Cardiology. 2002;97:203-9.

42. Mitchell A, Guan W, Staggs R, Hamel A, Hozayen S, Adhikari N, Grindle S, Desir S, John R, Hall JL, Eckman P. Identification of differentially expressed transcripts and pathways in blood one week and six months following implant of left ventricular assist devices. PLoS One. 2013;8:e77951.

43. de Weger RA, Schipper ME, Siera-de Koning E, van der Weide $P$, van Oosterhout MF, Quadir R, Steenbergen-Nakken H, Lahpor JR, de Jonge N, Bovenschen N. Proteomic profiling of the human failing heart after left ventricular assist device support. J Heart Lung Transplant. 2011;30:497-506.

44. Mehra MR, Uriel N, Naka Y, Cleveland JC Jr, Yuzefpolskaya M, Salerno CT, Walsh MN, Milano CA, Patel CB, Hutchins SW, et al. A fully magnetically levitated left ventricular assist device - final report. N Engl J Med. 2019;380: $1618-27$.

\section{Publisher's Note}

Springer Nature remains neutral with regard to jurisdictional claims in published maps and institutional affiliations.

\section{Ready to submit your research? Choose BMC and benefit from:}

- fast, convenient online submission

- thorough peer review by experienced researchers in your field

- rapid publication on acceptance

- support for research data, including large and complex data types

- gold Open Access which fosters wider collaboration and increased citations

- maximum visibility for your research: over $100 \mathrm{M}$ website views per year

At BMC, research is always in progress.

Learn more biomedcentral.com/submission 